\title{
The Effect of Pre-exercise Ingestion of Corinthian Currant on Endurance Performance and Blood Redox Status.
}

Chariklia K. Deli ${ }^{\mathrm{a}}$, Athanasios Poulios ${ }^{\mathrm{a}}$, Kalliopi Georgakoulia ${ }^{\mathrm{a}}$, Konstantinos Papanikolaou ${ }^{\mathrm{a}}$, Alexandros Papoutsis ${ }^{b}$, Maria Selemekou ${ }^{c}$, Vaios T. Karathanos ${ }^{b, d}$, Dimitris Draganidis ${ }^{a}$, Athanasios Tsiokanos $^{\text {a }}$, Yiannis Koutedakis ${ }^{\text {a,e }}$, Ioannis G. Fatouros ${ }^{\text {a }}$, Athanasios Z. Jamurtas ${ }^{a^{*}}$

${ }^{a}$ Laboratory of Exercise Physiology, Athletic Biochemistry, and Sports Nutrition, School of Physical Education and Sport Science, University of Thessaly, Greece; ${ }^{b}$ Laboratory of ChemistryBiochemistry-Physical Chemistry of Foods, Department of Nutrition, Harokopio University, Greece; ${ }^{c}$ Department of Biochemistry and Biotechnology, University of Thessaly, Greece; ${ }^{d}$ Agricultural Cooperatives' Union of Aeghion, Aeghion 25100, Greece; ${ }^{e}$ School of Sports, Performing Arts and Leisure, University of Wolverhampton, Wolverhampton, UK

*Corresponding author: Athanasios Z. Jamurtas, ajamurt@pe.uth.gr School of Physical Education and Sport Science, University of Thessaly, Karies, 42100 Trikala, Greece

\begin{abstract}
The Effect of Pre-exercise Ingestion of Corinthian Currants on Endurance Performance and Blood Redox Status

The present study investigated the effect of Corinthian currant pre-exercise supplementation on metabolism, performance and blood redox status during, and after prolonged exercise. Eleven healthy participants (21-45y) performed a 90-min constant-intensity $\left(60-70 \% \mathrm{VO}_{2 \max }\right)$ submaximaltrial, plus a time-trial (TT) to exhaustion $\left(95 \% \mathrm{VO}_{2 \max }\right)$ after consuming an isocaloric $(1.5 \mathrm{~g} \mathrm{CHO} / \mathrm{kg}$ $\mathrm{BM}$ ) amount of randomly assigned Corinthian currant or glucose-drink, or water (control). Blood was drawn at baseline, pre-exercise, 30min, $60 \mathrm{~min}$, 90min of submaximal-trial, post-TT, and $1 \mathrm{~h}$ post-TT. Post-ingestion blood glucose (GLU) under Corinthian currant was higher compared with water, and similar compared with glucose-drink throughout the study. Respiratory quotient under Corinthian currant was similar with glucose-drink and higher than water throughout the submaximal trial. Accordingly, higher $\mathrm{CHO}$ and lower fat oxidation were observed under Corinthian currant compared with water. The TT performance was similar between Corinthian currant, glucose-drink and water. Redox status were similar under all three conditions. Reduced glutathione (GSH) declined while total antioxidant capacity (TAC) and uric acid increased during exercise. GSH and TAC returned to baseline, while uric acid remained increased the following $1 \mathrm{~h}$. Corinthian currant, although did not alter exercise-mediated redox status changes and performance, was equally effective to a glucose-drink in maintaining GLU levels during prolonged cycling.
\end{abstract}

Keywords: raisins supplementation; glucose homeostasis; oxidative stress; prolonged cycling

\section{Introduction}

Aerobic exercise performance in events lasting more than one hour has been shown to improve with pre- or/and during-exercise ingestion of carbohydrates (CHO) (Campbell, Prince, Braun, Applegate, \& Casazza, 2008; Coggan and Coyle, 1987; Febbraio, Chiu, Angus, Arkinstall, \& Hawley, 2000; Pöchmüller, Schwingshackl, Colombani, \& Hoffmann, 2016; Tsintzas, Williams, Wilson, \& Burrin, 1996), and athletes or recreationally exercised individuals are often consume CHO before, and/or during exercise. The improvement in performance with $\mathrm{CHO}$ supplementation is due to the maintenance of blood glucose (GLU) levels (Campbell, et al., 2008; Febbraio, et al., 2000; Utter, et al., 2004) and the increased CHO availability for oxidation late in exercise (Jeukendrup, et al., 1999; Utter, et al., 2004) that may preserve muscle glycogen stores (Harger-Domitrovich, McClaughry, Gaskill, \& Ruby, 2007; Stellingwerff, et al., 2007), or may not (Utter, et al., 2004). Apparently based on the above mechanisms, the dietary industry provides a wide range of $\mathrm{CHO}$ supplements (sport drinks, sport gels, CHO bars, sport jellybeans, sport chews) aiming at optimizing performance during training or competitions. However, these products are processed, and often expensive, in contrast with other natural foods that may provide a healthier, though, equally effective choice. For 
example, pre-exercise ingestion of $\mathrm{CHO}$ in the form of bananas (Murdoch, Bazzarre, Snider, \& Goldfarb, 1993) or honey (Earnest, et al., 2004), has been reported to effectively maintain blood GLU and improve performance compared with placebo. Identifying more natural foods and establishing their effectiveness in maintaining euglycemia during exercise and probably improving performance, would be of great importance for those engaging in endurance training and/or competitions, providing them with more alternatives to choose the best-fitting choice of $\mathrm{CHO}$ source to their needs.

Raisins are reported in history books as far ago as 2000BC in Persia and Egypt; they are mentioned in the Bible (Numbers 6:3) during the time of Moses (Britannica). In ancient Greece and Rome, soldiers would carry raisins in the battlefield as a rich energy source, while winners of athletic events would receive raisins as payment. These historical facts indicate that the ancient Greeks and Romans perceived raisins as a potent performance enhancing food, while in the recent years they are well known for their potential health benefits (Kaliora, et al., 2008 ; Williamson and Carughi, 2010). Corinthian currants are small, dark purple-colored, sun-dried vine products, produced from black grapes (Vitis Vinifera L., var. Apyrena) and cultivated almost exclusively in the Southern Greece. Corinthian currants consist a high source of complex CHO (32.5\% glucose, $32.1 \%$ fructose, $0.40 \%$ sucrose, $0.72 \%$ maltose), minerals (magnesium, iron, potassium, phosphorus, zinc) and vitamins (ascorbic acid, pyridoxine, riboflavin and thiamin) necessary for vitality. Additionally, currants are considered as dried fruits with low-to-moderate glycemic index (Kanellos, et al., 2013), and they contain virtually no fat or cholesterol (Nikolidaki, et al., 2017). Despite their rich $\mathrm{CHO}$ content, there is limited data regarding the ergogenic potential of raisins during prolonged endurance exercise (Kern, Heslin, \& Rezende, 2007; Rietschier, et al., 2011; Too, et al., 2012). This data suggests that raisins may consist an equally effective form of $\mathrm{CHO}$ to other commercial products, on maintaining euglycemia and improving performance.

Aerobic exercise and training relates with the production of reactive oxygen and nitrogen species (RONS), evidenced by the changes in the concentration of several by-products deriving from the oxidation of biomolecules, and the upregulation of antioxidant enzymes (Aguilo, et al., 2005; Andersson, Karlsen, Blomhoff, Raastad, \& Kadi, 2010; Bloomer, Goldfarb, \& McKenzie, 2006; Chatzinikolaou, et al., 2014; Zalavras, et al., 2015). Although RONS in low to moderate quantities are essential for optimized exercise performance and exercise-induced adaptations (Gomez-Cabrera, et al., 2006; Reid, 2001), yet, excessive production of RONS especially during exhaustive exercise, promotes contractile dysfunction, muscle weakness and fatigue, and impaired recovery from exercise (Powers and Jackson, 2008; Reid, 2001). There is evidence that treating with antioxidants, protects in part against RONS-mediated damage in exercise (Kalafati, et al., 2010; Sureda, Ferrer, Mestre, Tur, \& Pons, 2013). In regards with this prospective, the supplementation of antioxidants is a common strategy to minimize RONS production and avoid the detrimental effects of oxidative stress in exercise (Michailidis, et al., 2013; Sadowska-Krepa, et al., 2017). Their rich content in polyphenols (Chiou, et al., 2007; Chiou, Panagopoulou, Gatzali, De Marchi, \& Karathanos, 2014) which are free radicals scavengers (Chiou, et al., 2007), renders Corinthian currant a potentially capable nutrient to boost an individual's antioxidant status in response to an acute bout of prolonged aerobic exercise, and provides an alternative antioxidant source for those seeking a more healthy option. However, to our knowledge, no study so far has addressed this issue. The only study (Skarpanska-Stejnborn, Basta, \& Pilaczynska-Szczesniak, 2006) that examined the influence of black currant (Ribes nigrum) extract on the endogenous antioxidant defence of rowers, used chronic instead of acute supplementation, providing evidence of improved protection against exercise-related oxidative processes.

The purpose of the present study was to investigate the effect of pre-exercise supplementation of Corinthian currant on metabolism and performance, as well as redox status in response to prolonged aerobic exercise. These responses were compared against glucose and water.

\section{Methods \\ Participants}

According to a preliminary power analysis (a probability error of 0.05 , and a statistical power of $80 \%$ ), a sample size of 10 subjects per group was considered appropriate in order to detect statistically meaningful changes between groups. Power analysis estimations were based on studies 
that examined the effects of acute exercise on metabolic and cardiorespiratory parameters (i.e. blood GLU, lactate) (Kern, et al., 2007; Too, et al., 2012), and the effects of acute exercise on redox biochemical variables [i.e. glutathione $(\mathrm{GSH})$, catalase, total antioxidant capacity (TAC), thiobarbituric reactive substances (TBARS)] (Nikolaidis, et al., 2006; Paschalis, et al., 2007). Eleven healthy recreationally trained male $(n=9)$ and female $(n=2)$ adults $(20-45 y)$ participated in the present controlled, randomized cross over study. Participation criteria included a normal BMI, absence of lower-limb musculoskeletal injury, metabolic diseases, drug/supplement consumption, and aerobic fitness $\left(\mathrm{VO}_{2 \max }>35 \mathrm{ml} / \mathrm{kg} / \mathrm{min}\right)$. Baseline anthropometry is presented in Table 1 . Participants provided written informed consent. Procedures were in accordance with the 1975 Declaration of Helsinki, and was approved by the University of Thessaly Research and Ethics Committee. The study is registered at ClinicalTrials.gov, Identifier: NCT03288064.

\section{Carbohydrate supplementation - liquid ingestion}

Thirty minutes prior to the exercise session, and within a timeframe of $5 \mathrm{~min}$, participants consumed an isocaloric amount $(1.5 \mathrm{~g} \mathrm{CHO} / \mathrm{kg} \mathrm{BW})$ of: a) Corinthian currants (an average $75 \mathrm{~kg}$ individual needs to ingest $\sim 112$ gr or 2/3 of a tea-cup) or b) glucose-drink (Top Star 100, Esteriplas, Portugal), or c) water alone (7 ml/kg BW) (control). Fluid intake was constant at $7 \mathrm{ml} / \mathrm{kg} \mathrm{BW}$ before exercise, $3 \mathrm{ml} / \mathrm{kg} \mathrm{BW}$ every $20 \mathrm{~min}$ during the 90 -min trial, and $7 \mathrm{ml} / \mathrm{kg} \mathrm{BW}$ within $15 \mathrm{~min}$ after exercise.

\section{Study design}

The study design is presented in Figure 1. The participants visited the laboratory four times in total. During their first visit, body mass (Beam Balance 710; Seca, Birmingham, United Kingdom), and standing-height (Stadiometer 208; Seca) were assessed. Body fat was calculated from 7 skinfoldthickness measures with a Harpenden caliper (John Bull, St Albans, United Kingdom) through Siri equation. $\mathrm{VO}_{2 \max }$ was assessed through a respiratory analyzer (CareFusion, Viasis). Both the protocol for the assessment of $\mathrm{VO}_{2 \max }$, and the exercise protocol were performed on a cycle ergometer (Cycloergometer, Monark 834, ERGOMED C, Sweeden). During their second visit (within the following week), the participants were randomly assigned to one of the three experimental conditions and performed the exercise protocol. During their third and fourth visits, the participants repeated the experimental procedure after they had been assigned to one of the remaining conditions. Between treatments, there was a wash out period of two weeks. The head of the laboratory, using a 3-period, 3-treatment crossover design, determined the order of treatment administration. Blood was drawn at baseline, $30 \mathrm{~min}$ post-supplementation (pre-exercise), and at 30, 60 , and 90 min of submaximal trial, after exhaustion (TT), and $1 \mathrm{~h}$ post-exercise, for the assessment of GSH, catalase, uric acid, TAC, and TBARS.

\section{$\mathrm{VO}_{2 \max }$ assessment protocol}

Following an 8-min warm-up cycling (80-100rpm) on a cycle ergometer (Monark 834, ERGOMED C, Sweeden) and 5-min stretching exercises, the participants' aerobic capacity was assessed. Participants cycled at a constant velocity of 60-70rpm until exhaustion, with an additional weight of $1 \mathrm{~kg}$ during the first minute; afterwards, additional weight was added progressively as follows: $0.5 \mathrm{~kg}$ during the second minute and $0.5 \mathrm{~kg}$ every $2 \mathrm{~min}$ thereafter. Gas exchange was monitored through the respiratory analyzer (CareFusion, Viasis). Heart rate was recorded every $1 \mathrm{~min}$.

\section{Experimental exercise protocol}

Prior to exercise, the participants performed the warm-up that was used during the $\mathrm{VO}_{2 \max }$ assessment. The exercise protocol, consisted of $90 \mathrm{~min}$ of cycling at $60 \%-70 \% \mathrm{VO}_{2 \max }$, followed by a TT at $95 \% \mathrm{VO}_{2 \max }$ to exhaustion. Gas exchange was monitored for the first $15 \mathrm{~min}$ until the desired steady state was established, at $30 \mathrm{~min}$, and every $25 \mathrm{~min}$ for $5 \mathrm{~min}$ thereafter.

\section{Blood collection and handling}

Blood samples $(10 \mathrm{~mL})$ were drawn from a forearm vein and plasma (assessment of TBARS, TAC, uric acid), and red blood cells lysate (assessment of GSH, catalase) were collected and stored as previously described (Deli, et al., 2017; Theodorou, et al., 2010). A small portion of whole blood 
$(0.5 \mu \mathrm{L})$ was used for the assessment of lactic acid (LA). Blood samples were stored in multiple aliquots at $-80^{\circ} \mathrm{C}$ and thawed only once before the analyses.

\section{Assays \\ Metabolism}

Blood glucose (GLU) was estimated in a Clinical Chemistry Analyzer Z1145 (Zafiropoulos Diagnostica, Athens, Greece) with commercially available kits (Zafiropoulos, Athens, Greece). The intra- and inter-assay for GLU was $4.9 \%$ and $3.8 \%$, respectively.

Lactate was measured in a microphotometer (DR LANGE, Berlin) with commercially available kits (LCQ 140, DR LANGE, Berlin). The intra- and inter-assay for LA was $2.4 \%$ and $3.9 \%$.

\section{Redox status}

TBARS, GSH, catalase, and TAC were determined in a HITACHI, U-1900 spectrophotometer as previously described (Theodorou, et al., 2010). The intra- and inter-assay CV for TBARS were $6.7 \%$ and $5.9 \%$, for GSH $5.7 \%$ and $4.5 \%$, for catalase $6.2 \%$ and $10.0 \%$, and for TAC $2.1 \%$ and $5.4 \%$, respectively.

Uric acid was estimated in a Clinical Chemistry Analyzer Z1145 (Zafiropoulos Diagnostica, Athens, Greece) with commercially available kits (Zafiropoulos, Athens, Greece). The intra- and inter-assay $\mathrm{CV}$ for uric acid was $2.12 \%$ and $3.4 \%$, respectively.

For all of the above markers, each sample was analyzed in duplicates.

\section{Dietary analysis}

The participants recorded their usual diet 3 days prior to exercise bouts and received a copy of their dietary record sheets, so that they would follow exactly the same diet before their second and third experimental session. Dietary records were analyzed with ScienceFit Diet 200A (Science Technologies, Athens, Greece). Participants' diet is summarized in Table 1.

\section{Calculations of $\mathrm{CHO}$ and fat oxidation}

Carbohydrate and lipid oxidation was calculated using the Frayn equations assuming protein oxidation was zero as previously described (Rietschier, et al., 2011):

$$
\begin{aligned}
& \text { CHO oxidation }(\mathrm{g} / \mathrm{min})=4.58 \times \mathrm{V}_{\mathrm{CO}_{2}}-3.23 \times \mathrm{V}_{\mathrm{O}_{2}} \\
& \text { Fat oxidation }(\mathrm{g} / \mathrm{min})=1.70 \times V_{\mathrm{O}_{2}}-1.69 \times \mathrm{V}_{\mathrm{CO}_{2}}
\end{aligned}
$$

\section{Statistical analysis}

The normality of the sample distribution was examined with a Kolmogorov-Smirnov test. TT and TBARS were subjected to logarithmic transformation as previously described (Brown, Child, Day, \& Donnelly, 1997). All dependent variables (except for TT) were analyzed using a two-way ANOVA (treatment $\times$ time) with repeated measures on time. When significant main effects or interactions existed, Sidak pairwise comparisons were performed. Treatment effects on TT were examined through a one-way ANOVA with Sheffe post hoc measurements. Statistical significance was set at $\mathrm{p}<0.05$. Statistical analyses were performed with SPSS, version PASW 18.0 (SPSS Inc., Chicago, Ill.). The results are presented as M \pm SEM.

\section{Results \\ Metabolic responses}

Time main effect existed for GLU $\left[\mathrm{F}_{(2.731,96)}=6.154\right.$, partial $\left.\eta^{2}=0.278, \mathrm{p}<0.01\right]$, and LA $\left[\mathrm{F}_{(2.554,14)}=\right.$ 50.874, partial $\eta^{2}=0.728, \mathrm{p}<0.001$ concentration, while main effect of condition existed for GLU concentration $\mathrm{F}_{(1,16)}=4.732$, partial $\eta^{2}=0.372$, $\left.\mathrm{p}<0.05\right)$ ].

Glucose concentration decreased $1 \mathrm{~h}$ post-TT, compared with 30 and 60 min of exercise, and was higher post-TT compared with 90min of exercise under all conditions. Corinthian currant exhibited higher blood GLU compared with water, while similar compared with glucose-drink throughout the study (Figure 2). 
Lactic acid increased at 30, 60, and 90 min of submaximal exercise, and peaked post-TT compared with baseline under all three conditions (Figure 2).

\section{Cardiorespiratory responses during submaximal exercise}

Time main effect existed for $\mathrm{CO}_{2}$ production $\left[\mathrm{F}_{(2,58)}=4.653\right.$, partial $\left.\eta^{2}=0.138, \mathrm{p}<0.05\right]$, respiratory quotient $(\mathrm{RQ})\left[\mathrm{F}_{(2,58)}=5.796,\left(\eta^{2}=0.167\right), \mathrm{p}<0.01\right.$, ventilation $(\mathrm{VE})\left[\mathrm{F}_{(2,58)}=6.363\right.$, partial $\eta^{2}=$ $0.180, \mathrm{p}<0.01$, CHO oxidation $\left[\mathrm{F}_{(2,58)}=4.996,\left(\eta^{2}=0.147\right), \mathrm{p}<0.05\right.$ and fat oxidation $\left[\mathrm{F}_{(2,58)}=5.019\right.$, $\left.\left(\eta^{2}=0.148\right), p=0.010\right]$. Main effect of condition existed for RQ $\left[F_{(2,29)}=4.606,\left(\eta^{2}=0.241\right)\right.$, $\mathrm{p}<0.05]$, CHO oxidation $\left[\mathrm{F}_{(2,29)}=4.088,\left(\eta^{2}=0.220\right), \mathrm{p}<0.05\right]$, while main effect of condition reached significance for fat oxidation $\left[\mathrm{F}_{(2,29)}=3.306,\left(\eta^{2}=0.186\right), \mathrm{p}=0.051\right]$.

$\mathrm{CO}_{2}$ production was higher at 90 min compared with $60 \mathrm{~min}$ of submaximal exercise under all conditions (Table 3). RQ decreased at 60 and 90 min compared with $30 \mathrm{~min}$ of exercise in all conditions. However, RQ under Corinthian currant was higher compared to water condition, while similar with glucose throughout the submaximal trial (Table 3). Ventilation was higher at $90 \mathrm{~min}$ compared with 30 and 60 min of submaximal trial in all conditions (Table 2).

$\mathrm{CHO}$ oxidation was lower at $60 \mathrm{~min}$ compared with $30 \mathrm{~min}$ and $90 \mathrm{~min}$ of submaximal trial in all conditions. Fat oxidation was higher at 60 min compared with 30 min of submaximal trial in all conditions. However, $\mathrm{CHO}$ oxidation under Corinthian currant was higher and fat oxidation lower compared with water, while similar compared with glucose, throughout the study (Table 2).

Oxygen consumption $\left(\mathrm{VO}_{2}\right)(\mathrm{L} / \mathrm{min})$ and relative to body mass $\mathrm{VO}_{2}(\mathrm{ml} / \mathrm{kg} \mathrm{BM} / \mathrm{min})$ were similar throughout the submaximal trial between conditions (Table 2).

\section{Performance}

Similar performance was observed between the three conditions ( $>0.05)$. TT (sec) was $79 \pm$ $16.3,94 \pm 16.3$, and $77 \pm 16.3$ for Corinthian currant, glucose-drink, and water, respectively.

\section{Redox status}

Time main effect existed for GSH $\left[\mathrm{F}_{(2.972,108)}=12.045\right.$, partial $\left.\eta^{2}=0.401, \mathrm{p}<0.001\right]$, uric acid $\left[\mathrm{F}_{(2.426,102)}=23.783\right.$, partial $\eta^{2}=0.583, \mathrm{p}<0.001$, and $\mathrm{TAC}\left[\mathrm{F}_{(2.851,114)}=8.944\right.$, partial $\eta^{2}=$ $0.320, \mathrm{p}<0.001]$. No main effects or interactions existed for TBARS and catalase.

GSH decreased throughout the submaximal exercise and post-TT, and returned at baseline levels $1 \mathrm{~h}$ post-TT in all conditions (Figure 3). Uric acid increased throughout the submaximal exercise and post-TT, and remained higher than baseline $1 \mathrm{~h}$ post-TT in all conditions (Figure 3). TAC increased at $30 \mathrm{~min}, 60 \mathrm{~min}$, and post-TT, and remained higher than baseline $1 \mathrm{~h}$ post-TT in all conditions (Figure 3). Redox status changes were similar between conditions throughout the study.

\section{Discussion}

The main findings from this study indicate that Corinthian currant exhibit similar metabolic and cardiorespiratory responses to those of the glucose drink. Euglycemia was maintained under all three conditions throughout the study. However, higher blood GLU was observed under Corinthian currant compared with water condition. Performance outcome was similar between $\mathrm{CHO}$ treatments and water. Redox status responses to prolonged cycling between Corinthian currants, glucose-drink and water pre-exercise ingestion are similar.

\section{Metabolic responses - Performance}

Euglycemia during prolonged exercise (Campbell, et al., 2008; Coggan and Coyle, 1987; Febbraio, et al., 2000) in conjunction with the preservation of muscle and liver glycogen (Harger-Domitrovich, et al., 2007; Stellingwerff, et al., 2007) may delay the onset of fatigue and subsequently, enhance exercise performance (Coyle, Coggan, Hemmert, \& Ivy, 1986). In the present study, euglycemia was maintained during submaximal cycling under all conditions. However, blood GLU under Corinthian currant, was higher compared with water but comparable with glucose-drink condition. These results indicate that, both $\mathrm{CHO}$ supplement forms are equally effective in maintaining blood GLU concentration and further support the hypothesis of pre-exercise $\mathrm{CHO}$ ingestion-mediated euglycemia (Campbell, et al., 
2008; Febbraio, et al., 2000). To our knowledge, only three other studies examined the effectiveness of raisins against other commercial products, on maintaining blood GLU during prolonged exercise (Kern, et al., 2007; Rietschier, et al., 2011; Too, et al., 2012). Of these studies, only one (Too, et al., 2012) used a placebo condition of water, and similarly with our results, the investigators also reported similar blood GLU under raisin and CHO chews, while higher blood GLU under CHO chews compared with water ingestion, during $80 \mathrm{~min}$ of treadmill running at $75 \% \mathrm{VO}_{2 \max }$. Likewise, although no water condition included, comparable blood GLU levels during an 80-min cycling are reported under sun-dried raisins and sport jellybeans (Rietschier, et al., 2011), or under raisins and sport gel (Kern, et al., 2007) pre-exercise supplementation.

In the present study, the type of CHO ingested did not affect blood lactate although, considering the higher blood GLU concentration, we would expect accordingly higher lactate concentration under Corinthian currant compared to water condition; instead, lactate similarly increased from baseline under all three conditions throughout the study. Comparable lactate responses during submaximal exercise have previously been reported between $\mathrm{CHO}$ ingestion and placebo condition (Hargreaves, Costill, Coggan, Fink, \& Nishibata, 1984). Likewise, lactate responses were not differently modified when raisins were compared to sport gel (Kern, et al., 2007), or CHO chews (Too, et al., 2012).

In the present study, Corinthian currant exhibited higher RQ than water condition throughout the submaximal exercise trial. Additionally, Corinthian currant supplementation demonstrated higher $\mathrm{CHO}$ and lower fat oxidation compared with water condition, throughout the submaximal exercise. These findings further support the greater $\mathrm{CHO}$ utilization during prolonged exercise with pre-exercise CHO ingestion (Febbraio, et al., 2000; Hargreaves, et al., 1984; Tsintzas, et al., 1996; Utter, et al., 2004). Additionally, our results suggest that Corinthian currant promotes the use of $\mathrm{CHO}$ equally to a glucose-drink, probably allowing for lower utilization of muscle glycogen (Tsintzas, Williams, Boobis, \& Greenhaff, 1995). This suggestion is reinforced by the higher blood CLU levels under Corinthian currant compared with water condition. Too et al. (2012), also reported greater energy contribution from raisins compared to water, at the last 20 min of submaximal treadmill running.

In our study, the higher GLU concentration and the greater utilization of $\mathrm{CHO}$ for energy production during submaximal exercise under Corinthian currant compared to water condition, did not translate into better performance, contrary to the majority of previous research (Campbell, et al., 2008; Febbraio, et al., 2000; Tsintzas, et al., 1996). The greater TT under GLU was perhaps due to better absorption of the liquid form of CHO; yet, this difference was not significant. Probably the observed metabolic differences were not great enough to significantly alter performance outcomes. In contrast, Too et al. (2012) reported faster TT under both $\mathrm{CHO}$ chews and raisins over water condition. However, in that study, instead of submaximal cycling and a TT at $95 \% \mathrm{VO}_{2 \max }$ to exhaustion, treadmill running and a 5-km TT was used. The different type and consequently different demands of the exercise protocol and TT (Jeukendrup and Killer, 2010), probably account for this inconsistency. Febbraio et al. (2000), report improved performance with CHO ingestion, but only when the ingestion is maintained throughout exercise. In our study, CHO feeding was applied only preexercise, whereas in the study of Too et al. (2012) CHO ingestion was maintained during exercise, and this may also explain the different performance outcome. Nevertheless, when comparing raisins against other commercial $\mathrm{CHO}$ sources, similar performance outcomes are demonstrated (Kern, et al., 2007; Rietschier, et al., 2011). Rietschier et al. (2011), report similar performance at $10-\mathrm{km}$ TT when raisins or sport jellybeans are ingested during the preceding 2-h submaximal cycling. Similarly, Kern et al. (2007) recorded similar performance at a 15-min TT with both raisins and sport gel feeding during the preceding 45min submaximal cycling. However, in that study, the short duration of exercise $(<1 \mathrm{~h})$ can justify these results, since, in no glycogen-limited situations performance enhancement is rather due to a central nervous system-based mechanism, while the type and/or amount of $\mathrm{CHO}$ and its ability to be absorbed and oxidized appear irrelevant (Carter, Jeukendrup, \& Jones, 2004; Stellingwerff and Cox, 2014). More research is needed to clarify the ergogenic 
effectiveness of Corinthian currant and the most favorable feeding mode and timing of supplementation.

\section{Redox responses}

According with previous research (Aguiló, Tauler, Gimeno, Fuentespina, \& Pons, 2000; Bulduk, N., Baltac, \& Gümüş, 2011; Zalavras, et al., 2015), in the present study, prolonged cycling at $60-70 \%$ of $\mathrm{VO}_{2 \max }$ followed by a maximal TT to exhaustion modified the endogenous antioxidants. More specific, GSH declined after the first $30 \mathrm{~min}$ and remained in lower than baseline levels throughout the submaximal exercise and post-TT, and returned in baseline levels $1 \mathrm{~h}$ later. GSH reduction is probably due to its extended use against the increased RONS production. Upregulation of plasma antioxidants was evidenced as uric acid and TAC elevated throughout exercise. Uric acid is also reported to be increased after a marathon run (Rokitzki, et al., 1994), and TAC was elevated after a half-marathon (Child, Wilkinson, Fallowfield, \& Donnelly, 1998). Uric acid is one of the major plasma antioxidants, and the major determinant of TAC, and changes in uric acid mostly resemble changes in TAC (Therond, Bonnefont-Rousselot, Davit-Spraul, Conti, \& Legrand, 2000). Therefore, the rise of uric acid and TAC probably reflects one of the body's protective mechanisms against exercise-induced RONS generation. In the present study, prolonged cycling did not change lipid oxidation, as there were no significant changes in TBARS levels. Similarly with previous findings (Bloomer, et al., 2006), although contrary with others (Rokitzki, et al., 1994), prolonged cycling in the present study, did not affect the oxidation of lipids. It seems that the increased use of GSH, but also the upregulation of uric acid and TAC, were effective against lipid peroxidation, and this could justify in part the absence of changes in catalase. In the present study, protein or DNA oxidation were not assessed, and this comprises a limitation; future research should incorporate related markers.

In the present study, redox status changes were similar under all conditions. Unfortunately, there is no previous data to compare our results. The fact that, there was no altered response of the oxidative stress markers under Corinthian currant against the other two conditions, despite the increased antioxidant capacity of raisins (Chiou, et al., 2007), may be due to the relatively low intensity of exercise, that was not capable of inducing different responses between treatments. The only previous study (Skarpanska-Stejnborn, et al., 2006) that examined the effects of raisin supplementation on redox status during exercise used chronic supplementation instead of acute pre-exercise ingestion, and raisin extract instead of dried fruit. In that study, 6 weeks of raisin extract supplementation resulted in lower TBARS, SOD and GPx activity, and higher TAC after a maximal rowing test compared with placebo (Skarpanska-Stejnborn, et al., 2006). The limited information so far, does not allow for any conclusion regarding the effect of acute pre-exercise ingestion or chronic supplementation of raisins in exercise-related changes in redox status. More studies are needed to elucidate this effect, as well as the appropriate amount, form, and timing of Corinthian currant ingestion.

\section{Conclusions}

Pre-exercise ingestion of Corinthian currant is equally effective with a glucose-drink in providing the $\mathrm{CHO}$ needed to maintain euglycemia and promote $\mathrm{CHO}$ oxidation during prolonged exercise. Therefore, it can be used as an alternative, natural and probably healthier, yet, equally effective choice to a glucose-drink regarding metabolic responses.

Corinthian currant did not provoke different TT performance and redox responses to the exercise stimulus of the present study. It is possible that a different TT and/or exercise protocol would result in a different performance outcome, and redox alterations of greater magnitude, and subsequently lead to different results.

Future research should incorporate both acute and chronic supplementation in the experimental design. Furthermore, the supplementation of Corinthian currant in a different form (e.g. currant extract, or juice) or a different feeding protocol, as well as exercise stimulus of longer duration and/or greater intensity should be applied. Finally, regarding redox status, except for lipid peroxidation, other markers of protein or DNA oxidation should be assessed 
to better describe the effect of Corinthian currant supplementation on exercise-related redox status parameters.

\section{Acknowledgments}

We would like to thank all the participants for their dedication to the study.

The study was designed by CKD, IGF, and AZJ; data were collected and analyzed by CKD, APo, KG, KP, APa, SM and DD; data interpretation was performed by CKD, IGF, YK, AT, VTK, and AZJ; preparation of the first version of the manuscript was undertaken by CKD, IGF, and AZJ. All authors reviewed and approved the final version of the paper.

\section{Disclosure of interest}

The authors report no conflicts of interest.

\section{References}

Aguiló, A. , P. Tauler, I. Gimeno, E. Fuentespina, and A. Pons. (2000). Changes in erythrocyte antioxidant enzymes during prolonged submaximal exercise. BioFactors (11), pp. 27-30

Aguilo, A., P. Tauler, E. Fuentespina, J. A. Tur, A. Cordova, and A. Pons. (2005). Antioxidant response to oxidative stress induced by exhaustive exercise. Physiol Behav, 84(1), pp. 1-7. doi:10.1016/j.physbeh.2004.07.034.

Andersson, H., A. Karlsen, R. Blomhoff, T. Raastad, and F. Kadi. (2010). Plasma antioxidant responses and oxidative stress following a soccer game in elite female players. Scand J Med Sci Sports, 20(4), pp. 600-608. doi:10.1111/j.1600-0838.2009.00987.x.

Bloomer, R. J., A. H. Goldfarb, and M. J. McKenzie. (2006). Oxidative stress response to aerobic exercise: comparison of antioxidant supplements. Med Sci Sports Exerc, 38(6), pp. 1098-1105. doi:10.1249/01.mss.0000222839.51144.3e.

Britannica, Encycopaedia-. http: //www.britannica.com/EBchecked/topic/489994/raisin Encycopaedia Britannica.

Brown, S. J., R. B. Child, S. H. Day, and A. E. Donnelly. (1997). Exercise-induced skeletal muscle damage and adaptation following repeated bouts of eccentric muscle contractions. J Sports Sci, 15(2), pp. 215-222. doi:10.1080/026404197367498.

Bulduk, Ö. E, Ergene. N., K. A. Baltac, and H. Gümüş. (2011). Plasma antioxidant responses and oxidative stress following a 20 meter shuttle run test in female volleyball players International Journal of Human Sciences 8(2).

Campbell, C., D. Prince, M. Braun, E. Applegate, and G. A. Casazza. (2008). Carbohydratesupplement form and exercise performance. Int J Sport Nutr Exerc Metab, 18(2), pp. 179190.

Carter, J. M., A. E. Jeukendrup, and D. A. Jones. (2004). The effect of carbohydrate mouth rinse on 1-h cycle time trial performance. Med Sci Sports Exerc, 36(12), pp. 2107-2111. 
Chatzinikolaou, A., D. Draganidis, A. Avloniti, A. Karipidis, A. Z. Jamurtas, C. L. Skevaki, ... I. Fatouros. (2014). The microcycle of inflammation and performance changes after a basketball match. Journal of Sports Sciences 32(9), pp. 870-882.

Child, R. B., D. M. Wilkinson, J. L. Fallowfield, and A. E. Donnelly. (1998). Elevated serum antioxidant capacity and plasma malondialdehyde concentration in response to a simulated half-marathon run. Med Sci Sports Exerc, 30(11), pp. 1603-1607.

Chiou, A. , V.T. Karathanos, A. Mylona, F. N. Salta, F. Preventi, and N. K. Andrikopoulos. (2007). Currants (Vitis vinifera L.) content of simple phenolics and antioxidant activity. Food Chemistry (102), pp. 516-522.

Chiou, A., E. A. Panagopoulou, F. Gatzali, S. De Marchi, and V. T. Karathanos. (2014). Anthocyanins content and antioxidant capacity of Corinthian currants (Vitis vinifera L., var. Apyrena). Food Chem, 146, pp. 157-165. doi:10.1016/j.foodchem.2013.09.062.

Coggan, A. R., and E. F. Coyle. (1987). Reversal of fatigue during prolonged exercise by carbohydrate infusion or ingestion. J Appl Physiol (1985), 63(6), pp. 2388-2395.

Coyle, E. F., A. R. Coggan, M. K. Hemmert, and J. L. Ivy. (1986). Muscle glycogen utilization during prolonged strenuous exercise when fed carbohydrate. J Appl Physiol (1985), 61(1), pp. 165-172.

Deli, C. K., I. G. Fatouros, V. Paschalis, A. Tsiokanos, K. Georgakouli, A. Zalavras, . . . A. Z. Jamurtas. (2017). Iron Supplementation Effects on Redox Status following Aseptic Skeletal Muscle Trauma in Adults and Children. Oxid Med Cell Longev, 2017, p 4120421. doi:10.1155/2017/4120421.

Earnest, C. P., S. L. Lancaster, C. J. Rasmussen, C. M. Kerksick, A. Lucia, M. C. Greenwood, . . R. B. Kreider. (2004). Low vs. high glycemic index carbohydrate gel ingestion during simulated 64-km cycling time trial performance. J Strength Cond Res, 18(3), pp. 466-472. doi:10.1519/R-xxxxx.1.

Febbraio, M. A., A. Chiu, D. J. Angus, M. J. Arkinstall, and J. A. Hawley. (2000). Effects of carbohydrate ingestion before and during exercise on glucose kinetics and performance. $J$ Appl Physiol (1985), 89(6), pp. 2220-2226.

Gomez-Cabrera, M. C., A. Martinez, G. Santangelo, F. V. Pallardo, J. Sastre, and J. Vina. (2006). Oxidative stress in marathon runners: interest of antioxidant supplementation. $\mathrm{Br} J$ Nutr, 96 Suppl 1, pp. S31-33.

Harger-Domitrovich, S. G., A. E. McClaughry, S. E. Gaskill, and B. C. Ruby. (2007). Exogenous carbohydrate spares muscle glycogen in men and women during $10 \mathrm{~h}$ of exercise. Med Sci Sports Exerc, 39(12), pp. 2171-2179. doi:10.1249/mss.0b013e318157a650.

Hargreaves, M., D.L. Costill, A. Coggan, W.J. Fink, and I. Nishibata. (1984). Effect of carbohydrate feedings on muscle glycogen utilization and exercise performance. Med Sci Sports Exerc, 16(3), pp. 219-222.

Jeukendrup, A. E., and S. C. Killer. (2010). The myths surrounding pre-exercise carbohydrate feeding. Ann Nutr Metab, 57 Suppl 2, pp. 18-25. doi:10.1159/000322698. 
Jeukendrup, A. E., A. Raben, A. Gijsen, J. H. Stegen, F. Brouns, W. H. Saris, and A. J. Wagenmakers. (1999). Glucose kinetics during prolonged exercise in highly trained human subjects: effect of glucose ingestion. J Physiol, 515 ( Pt 2), pp. 579-589.

Kalafati, M., A. Z. Jamurtas, M. G. Nikolaidis, V. Paschalis, A. A. Theodorou, G. K. Sakellariou, . . . D. Kouretas. (2010). Ergogenic and antioxidant effects of spirulina supplementation in humans. Med Sci Sports Exerc, 42(1), pp. 142-151. doi:10.1249/MSS.0b013e3181ac7a45.

Kaliora, A. C. , A. M. Kountouri, V. T. Karathanos, L. Koumbi, N. G. Papadopoulos, and N. K. Andrikopoulos. (2008). Effect of Greek Raisins (Vitis Vinifera L.) From Different Origins on Gastric Cancer Cell Growth. Journal Nutrition and Cancer 60(6), pp. 792-799.

Kanellos, P. T., A. C. Kaliora, C. Liaskos, N. K. Tentolouris, D. Perrea, and V. T. Karathanos. (2013). A study of glycemic response to Corinthian raisins in healthy subjects and in type 2 diabetes mellitus patients. Plant Foods Hum Nutr, 68(2), pp. 145-148. doi:10.1007/s11130013-0348-y.

Kern, M., C. J. Heslin, and R. S. Rezende. (2007). Metabolic and performance effects of raisins versus sports gel as pre-exercise feedings in cyclists. J Strength Cond Res, 21(4), pp. 12041207. doi:10.1519/R-21226.1.

Michailidis, Y., L. G. Karagounis, G. Terzis, A. Z. Jamurtas, K. Spengos, D. Tsoukas, . . I. G. Fatouros. (2013). Thiol-based antioxidant supplementation alters human skeletal muscle signaling and attenuates its inflammatory response and recovery after intense eccentric exercise. Am J Clin Nutr, 98(1), pp. 233-245. doi:10.3945/ajcn.112.049163.

Murdoch, S. D., T. L. Bazzarre, I. P. Snider, and A. H. Goldfarb. (1993). Differences in the effects of carbohydrate food form on endurance performance to exhaustion. Int J Sport Nutr, 3(1), pp. 41-54.

Nikolaidis, M.G., A.Z. Jamurtas, V. Paschalis, I.A. Kostaropoulos, A. Kladi-Skandali, V. Balamitsi, . . . D. Kouretas. (2006). Exercise-induced oxidative stress in G6PD-deficient individuals. Med. Sci. Sports Exerc., 38(8), pp. 1443-1450.

Nikolidaki, E. K., A. Chiou, M. Christea, A. P. Gkegka, M. Karvelas, and V. T. Karathanos. (2017). Sun dried Corinthian currant (Vitis Vinifera L., var. Apyrena) simple sugar profile and macronutrient characterization. Food Chem, 221, pp. 365-372. doi:10.1016/j.foodchem.2016.10.070.

Paschalis, V., M. G. Nikolaidis, I. G. Fatouros, G. Giakas, Y. Koutedakis, C. Karatzaferi, . . . A. Z. Jamurtas. (2007). Uniform and prolonged changes in blood oxidative stress after muscledamaging exercise. In Vivo, 21(5), pp. 877-883.

Pöchmüller, M., L. Schwingshackl, P.C. Colombani, and G. Hoffmann. (2016). A systematic review and meta-analysis of carbohydrate benefits associated with randomized controlled competition-based performance trials. Journal of the International Society of Sports Nutrition(13:27)doi:DOI 10.1186/s12970-016-0139-6.

Powers, S. K. , and M. J. Jackson. (2008). Exercise-Induced Oxidative Stress: Cellular Mechanisms and Impact on Muscle Force Production. Physiol Rev(88), pp. 1243-1276. 
497

498

499

500

501

502

503

504

505

506

507

508

509

510

511

512

513

514

515

516

517

518

519

520

521

522

523

524

525

526

527

528

529

530

531

532

533

Reid, M. B. . (2001). Plasticity in Skeletal, Cardiac, and Smooth Muscle Invited Review: Redox modulation of skeletal muscle contraction: what we know and what we don't. J Appl Physiol (90), pp. 724-731.

Rietschier, H. L., T. M. Henagan, C. P. Earnest, B. L. Baker, C. C. Cortez, and L. K. Stewart. (2011). Sun-dried raisins are a cost-effective alternative to Sports Jelly Beans in prolonged cycling. J Strength Cond Res, 25(11), pp. 3150-3156. doi:10.1519/JSC.0b013e31820f5089.

Rokitzki, L., E. Logemann, A. N. Sagredos, M. Murphy, W. Wetzel-Roth, and J. Keul. (1994). Lipid peroxidation and antioxidative vitamins under extreme endurance stress. Acta Physiol Scand, 151(2), pp. 149-158. doi:10.1111/j.1748-1716.1994.tb09732.x.

Sadowska-Krepa, E., B. Klapcinska, I. Pokora, P. Domaszewski, K. Kempa, and T. Podgorski. (2017). Effects of Six-Week Ginkgo biloba Supplementation on Aerobic Performance, Blood Pro/Antioxidant Balance, and Serum Brain-Derived Neurotrophic Factor in Physically Active Men. Nutrients, 9(8)doi:10.3390/nu9080803.

Skarpanska-Stejnborn, A., P. Basta, and L. Pilaczynska-Szczesniak. (2006). The influence of supplementation with the black currant (Ribes nigrum) extract on selected prooxidativeantioxidative balance parameters in rowers. Studies in Physical Calture and Tourism, 13(2), pp. 51 - 58.

Stellingwerff, T., H. Boon, A. P. Gijsen, J. H. Stegen, H. Kuipers, and L. J. van Loon. (2007). Carbohydrate supplementation during prolonged cycling exercise spares muscle glycogen but does not affect intramyocellular lipid use. Pflugers Arch, 454(4), pp. 635-647. doi:10.1007/s00424-007-0236-0.

Stellingwerff, Trent, and Gregory R. Cox. (2014). Systematic review: Carbohydrate supplementation on exercise performance or capacity of varying durations1. Applied Physiology, Nutrition \& Metabolism, 39(9), pp. 998-1011.

Sureda, A., M. D. Ferrer, A. Mestre, J. A. Tur, and A. Pons. (2013). Prevention of neutrophil protein oxidation with vitamins $C$ and $E$ diet supplementation without affecting the adaptive response to exercise. Int J Sport Nutr Exerc Metab, 23(1), pp. 31-39.

Theodorou, A. A. , M. G. Nikolaidis, V. Paschalis, G. K. Sakellariou, I. G. Fatouros, Y. Koutedakis, and A. Z. Jamurtas. (2010). Comparison between Glucose-6-Phosphate Dehydrogenase-Deficient and Normal Individuals after Eccentric Exercise. Med. Sci. Sports Exerc., 42(6), pp. 1113-1121.

Therond, P., D. Bonnefont-Rousselot, A. Davit-Spraul, M. Conti, and A. Legrand. (2000). Biomarkers of oxidative stress: an analytical approach. Curr Opin Clin Nutr Metab Care, 3(5), pp. 373-384.

Too, B. W., S. Cicai, K. R. Hockett, E. Applegate, B. A. Davis, and G. A. Casazza. (2012). Natural versus commercial carbohydrate supplementation and endurance running performance. $J$ Int Soc Sports Nutr, 9(1), p 27. doi:10.1186/1550-2783-9-27. 
534 Tsintzas, O.K. , C. Williams, L. Boobis, and P. Greenhaff. (1995). Carbohydrate ingestion

535 and glycogen utilization in different muscle fibre types in man. Journal of Physiology 489(1),

536 pp. 243-250.

537 Tsintzas, O.K., C. Williams, W. Wilson, and J. Burrin. (1996). Influence of carbohydrate 538 supplementation early in exercise on endurance running capacity. Med Sci Sports Exerc, 539 28(11), pp. 1373-1379.

540 Utter, A. C., J. Kang, D. C. Nieman, C. L. Dumke, S. R. McAnulty, D. M. Vinci, and L. S.

541 McAnulty. (2004). Carbohydrate supplementation and perceived exertion during prolonged 542 running. Med Sci Sports Exerc, 36(6), pp. 1036-1041.

543 Williamson, G., and A. Carughi. (2010). Polyphenol content and health benefits of raisins.

544 Nutr Res, 30(8), pp. 511-519. doi:10.1016/j.nutres.2010.07.005.

545 Zalavras, A., I. G. Fatouros, C. K. Deli, D. Draganidis, A. A. Theodorou, D. Soulas, . . A. Z. 546 Jamurtas. (2015). Age-related responses in circulating markers of redox status in healthy 547 adolescents and adults during the course of a training macrocycle. Oxid Med Cell Longev, 548 2015, p 283921. doi:10.1155/2015/283921.

549

550

551

552

553

554

555

556

557

558

559 
561 Table 1. Baseline characteristics and dietary analysis of the participants ${ }^{1}$.

\section{Anthropometric characteristics}

Age (years)

$33.27 \pm 2.43$

\begin{tabular}{lc}
\hline Body mass $(\mathrm{kg})$ & $73.0 \pm 2.6$ \\
\hline Height $(\mathrm{cm})$ & $172.0 \pm 0.03$ \\
\hline BMI $\left(\mathrm{kg} / \mathrm{m}^{2}\right)$ & $24.9 \pm 0.5$ \\
\hline Body fat $(\%)$ & $13.4 \pm 1.6$ \\
\hline $\mathrm{VO}_{2 \max }(\mathrm{ml} / \mathrm{kg} / \mathrm{min})$ & $46.2 \pm 1.9$
\end{tabular}

\section{Dietary analysis}

Daily energy intake (Kj/day)

$9,54 \pm 1,2$

Daily carbohydrate intake (\% of total energy content)

$51.2 \pm 3.2$

Daily fat intake (\% of total energy content)

$28.4 \pm 2.4$

Vitamin C (mg)

$91.0 \pm 21.0$

Vitamin E (mg)

$15.0 \pm 4.0$

${ }^{\mathrm{I}}$ Values are presented in $\mathrm{M} \pm \mathrm{SEM}$

562

563

564

565

566

567

568 
570 Table 2. Cardiopulmonary function during submaximal exercise trial ${ }^{1}$.

\begin{tabular}{|c|c|c|c|c|c|c|c|c|c|}
\hline & \multicolumn{3}{|c|}{ Corinthian currant } & \multicolumn{3}{|c|}{ Glucose-drink } & \multicolumn{3}{|c|}{ Water } \\
\hline & $30 \mathrm{~min}$ & $60 \mathrm{~min}$ & $90 \mathrm{~min}$ & $30 \mathrm{~min}$ & $60 \mathrm{~min}$ & $90 \mathrm{~min}$ & $30 \mathrm{~min}$ & $60 \mathrm{~min}$ & 90 min \\
\hline $\mathrm{VO}_{2}(\mathrm{~L} / \mathrm{min})$ & $2.2 \pm 0.12$ & $2.2 \pm 0.11$ & $2.2 \pm 0.13$ & $2.1 \pm 0.12$ & $2.2 \pm 0.11$ & $2.2 \pm 0.13$ & $2.2 \pm 0.12$ & $2.1 \pm 0.12$ & $2.3 \pm 0.13$ \\
\hline $\mathrm{VO}_{2}(\mathrm{ml} / \mathrm{kg} \mathrm{BW} / \mathrm{min})$ & $29.3 \pm 1.46$ & $29.5 \pm 1.70$ & $30.4 \pm 1.59$ & $28.5 \pm 1.46$ & $29.0 \pm 1.70$ & $29.9 \pm 1.59$ & $30.2 \pm 1.53$ & $29.3 \pm 1.78$ & $31.5 \pm 1.67$ \\
\hline $\mathrm{CO}_{2}(\mathrm{~L} / \mathrm{min})$ & $1.9 \pm 0.11$ & $1.9 \pm 0.10$ & $2.0 \pm 0.10^{\dagger}$ & $1.9 \pm 0.11$ & $1.8 \pm 0.10$ & $2.0 \pm 0.10^{\dagger}$ & $1.9 \pm 0.12$ & $1.8 \pm 0.10$ & $2.0 \pm 0.10^{\dagger}$ \\
\hline $\mathbf{R Q}$ & $0.91 \pm 0.01^{\#}$ & $0.89 \pm 0.01^{\dagger \#}$ & $0.90 \pm 0.01^{\dagger \#}$ & $0.87 \pm 0.01$ & $0.86 \pm 0.01^{\dagger}$ & $0.89 \pm 0.01^{\dagger}$ & $0.87 \pm 0.01$ & $0.85 \pm 0.01^{\dagger}$ & $0.85 \pm 0.01^{\dagger}$ \\
\hline VE (L/min) & $66 \pm 2.96$ & $66 \pm 2.58^{\dagger}$ & $71 \pm 3.30^{\dagger}$ & $58 \pm 2.95$ & $60 \pm 7.58^{\dagger}$ & $65 \pm 3.30^{\dagger}$ & $64 \pm 3.10$ & $60 \pm 2.70^{\dagger}$ & $66 \pm 3.46^{\dagger}$ \\
\hline $\begin{array}{l}\text { CHO oxidation } \\
\text { (g/min) }\end{array}$ & $2.0 \pm 0.15^{\#}$ & $1.8 \pm 0.11^{\dagger \#}$ & $2.0 \pm 0.16^{\dagger \#}$ & $1.5 \pm 0.15$ & $1.4 \pm 0.11^{\dagger}$ & $1.8 \pm 0.16^{\dagger}$ & $1.6 \pm 0.16$ & $1.3 \pm 0.39^{\dagger}$ & $1.5 \pm 0.17^{\dagger}$ \\
\hline Fat oxidation (g/min) & $0.37 \pm 0.05^{\#}$ & $0.45 \pm 0.05^{\dagger \#}$ & $0.40 \pm 0.06^{\#}$ & $0.48 \pm 0.05$ & $0.56 \pm 0.05^{\dagger}$ & $0.49 \pm 0.06$ & $0.54 \pm 0.06$ & $0.59 \pm 0.05^{\dagger}$ & $0.63 \pm 0.06$ \\
\hline $\mathrm{VO}_{2 \max }:$ Maximal oxy & consumption & $\mathrm{CO}_{2}:$ Carbon & lioxide produc & RQ: Respi & ry quotient; & E: Ventilati & CHO: Carbc & ates; ${ }^{\#}$ Diff & th from water \\
\hline
\end{tabular}

571 


\section{$573 \quad$ Figure legends}

574 Figure 1. Experimental design of the study. All participants were performed the three 575 experimental conditions in a randomized cross over study design.

576 Figure 2. Changes in glucose (A) and lactic acid (B) concentration during and after prolonged 577 submaximal aerobic exercise under black Corinthian currant (•), glucose ), and wate (

578 ) pre-exercise supplementation. "Significantly different from baseline in all conditions;

579 §Significantly different from $30 \mathrm{~min}$ in all conditions; ${ }^{*}$ Significantly different from $60 \mathrm{~min}$ in 580 all conditions; ${ }^{\dagger}$ Significantly different from previous time point in all conditions; 581 \#Significantly different between Corinthian currant and water condition at the same time 582 point.

583 Figure 3. Changes in the concentration of catalase (A), reduced glutathione (GSH) (B), 584 thiobarbituric reactive substances (TBARS) (C), total antioxidant capacity (TAC) (D), and 585 uric acid (E) during, and after prolonged cycling under the supplementation of black 586 Corinthian currant $(\bullet)$, glumse drink ( ), and ater alone ( ). *Significantly different 587 from baseline in all conditions; ${ }^{¥}$ Significantly different from pre-exercise; ${ }^{\S}$ Significantly 588 different from $30 \mathrm{~min}$ in all conditions; 